\title{
The Strategic Importance of Supplier Relationships in the Automotive Industry
}

Ove Brandes, Staffan Brege and Per-Olof Brehmer

\author{
Linköping University Post Print
}

\section{Tweet}

N.B.: When citing this work, cite the original article.

Original Publication:

Ove Brandes, Staffan Brege and Per-Olof Brehmer, The Strategic Importance of Supplier Relationships in the Automotive Industry, 2013, International Journal of Engineering Business Management, (5), 17.

http://dx.doi.org/10.5772/56257

Licensee: In-Tech / InTech http://www.intechweb.org/

Postprint available at: Linköping University Electronic Press

http://urn.kb.se/resolve?urn=urn:nbn:se:liu:diva-94247 


\title{
The Strategic Importance of Supplier Relationships in the Automotive Industry
}

\author{
Regular Paper
}

\author{
Ove Brandes ${ }^{1, *}$, Staffan Brege ${ }^{1}$ and Per-Olof Brehmer ${ }^{1}$ \\ 1 Department of Management and Engineering, Linköping University, Sweden \\ * Corresponding author E-mail: ove.brandes@liu.se \\ Received 8 June 2012; Accepted 16 December 2012
}

DOI: $10.5772 / 56257$

(c) 2013 Brandes et al.; licensee InTech. This is an open access article distributed under the terms of the Creative Commons Attribution License (http://creativecommons.org/licenses/by/3.0), which permits unrestricted use, distribution, and reproduction in any medium, provided the original work is properly cited.

Abstract The aim of this paper is to analyse longitudinally the development of purchasing strategies in the automotive industry during the last 20 years. The amplitude of the business cycle during this time frame has been very high and includes periods of financial/automotive crisis as well as high sales and demand. Our empirical data is primarily drawn from a 1990-2010 longitudinal case study of the relationship between automaker Volvo Personal Cars and Autoliv, a supplier of seat belts and airbags, complemented with secondary data framing the development of the industry level. The theoretical focus is on outsourcing and purchasing strategies developed within long-lasting buyer-supplier relationships; theoretical pillars are found in transaction-cost theories and the resource-based view of the firm.

Based on the longitudinal case study, our analysis pinpoints the importance of intimate cooperation between customer and supplier in areas close to the core values and core competences of the buyer (that is, the automaker). From an industry-level perspective, the winners in the automobile industry from 2010 and onwards have been and will be those who can organize long-term collaboration partnerships between the automakers, their suppliers, and the political stakeholders, and who can outsource a large part of the technical development to the suppliers in areas also close to the core competences. The automakers must accept that their suppliers have competing automakers as their customers and search for synergies in their product portfolio. Theoretically, there is a need for conceptual development through deeper studies of the firm's relational capability and its implications.

Keywords Supplier Relationships, Long-Term Cooperation, Technology Development, Automotive Industry

\section{Introduction}

The current crisis in the global automotive industry has two major driving forces. The financial crisis that began in September 2008 revealed the underlying structural problem, namely the long-term misfit between global supply and demand for personal cars (more than 20 per cent in volume [1] and with the large part in Europe). For 2012 an increase of up to 30 per cent is indicated. The total effect is the most dramatic change for the automotive industry since World War II, both in terms of finance, technology, and political influence on employment and location of factories. Also, pressure has increased on the automotive industry to reduce emissions. 
There are important differences in how the structural problems have affected the actors in the personal car supply chain. The automakers/OEMs (original equipment manufacturers) and the small and medium-sized suppliers have experienced more problems than the leading prime suppliers (such as Autoliv, Bosch/Nippondenso, and SKF). Car manufacturers in the premium segment (Audi and BMW) have been the most successful financially. However, they have now also been forced to consider whether they have gone too far in cost-cutting and global purchasing. They must question whether it is time to reconsider the relationships with suppliers, which over the years have become more arm's length (including relationships with non-US companies), and to increase cooperation with suppliers. A weak financial position can in itself force the OEMs in the premium segment to rely more on suppliers, a situation that has existed for a long time among low-volume producers, such as Volvo Car Corporation (Volvo), especially before Ford acquired the company in 1999.

The purpose of this article is to analyse the driving forces and strategies for buyer-supplier cooperation in areas close to the core values and core competences of the car manufacturers. This study's empirical example is Volvo and especially its relationship with Autoliv, a worldleading supplier of car safety products. The study covered a period from the beginning of the 1990s up to 2010, including the takeover of Volvo Personal Cars by Ford in 1999. During this period, Volvo changed strategy for many important parts and systems from in-house development to outsourcing and close innovative relationships. During the Ford era, Volvo also was integrated into Ford's global sourcing activities.

\section{Outsourcing in Theory}

The standard recipe for outsourcing, in the literature and also in practice, is to keep core activities and resources inhouse. For complementary resources and capabilities, partnership relations are recommended, and for standard solutions to buy "at arm's length" [2]. But what is considered core is changing over time.

Prahalad and Hamel [3] defined core competences as those technologies that help the company to stay ahead of competition over long time periods. Core competence will be transformed into value to customers, will be difficult to imitate, and will be useful for different products and markets. Other authors looked upon core competences not so much as technologies as core processes and capabilities, which may be based on internal competences and also may originate from strategic relationships [4]. Outsourcing also can be seen as a radical contrast to the conventional wisdom of competitive strategy $[5,6]$, since it is a way to achieve a combination of two strategies at the same time - cost leadership and differentiation.

\subsection{The Logics for Outsourcing}

In the literature, five different logics for outsourcing can be found: cost cutting, core competence focus, control, flexibility, and access to external resources.

The first logic is cost-cutting or lowest cost. Cost is often considered the most important criteria for an outsourcing decision [7,8]. A comparison has been made between the cost for in-house production and external sourcing [9]. However, different cost dimensions are emphasized in the literature.

Williamson [10] divided costs into production and transaction costs. With a transaction cost perspective, the company is primarily considered a governance structure. Transaction costs include a number of ex ante costs, such as drafting and negotiations, and ex post costs, such as monitoring and enforcing agreements [11]. A trade-off exists between transaction and production costs. In-house control will typically involve lower transaction costs, but, at the same time, will sacrifice the potential for economies of scale and the collective pooling of resources found in an outsourcing/market solution.

Analysis of the production function and production costs can be found among more traditional industrial organization scholars (see e.g., [12-14]). The potential for economies of scale and scope are often the most important aspects when outsourcing decisions are made. Other factors such as availability of raw materials and components, intellectual property rights, and a favourable geographical location are also important to the lowest cost logic [5].

The second logic is based on long-term competitiveness rooted in the corporation's core competence. By definition, the core competence has complex and systemic properties with tacit knowledge and competences embedded in organizational and cultural contexts $[3,15,16]$. Organizational learning is important for the development of core competence.

The strategic implication of this perspective is that

- $\quad$ core competence should be kept in-house;

- the availability of important complementary resources in partnership relationships should be secured;

- the supply of commodities should be found via the market mechanism [2,7]; and,

- outsourcing decisions might require upgrading of competence $[17,18]$. 
The concept of core competence has many aspects in common with Williamson's concept of transaction costs. Core competence is not a simple skill or asset [19], and can range from "what we do best" to what the customers value the highest [20]. Some researchers argue that the application of the resource-based view to outsourcing has been the most vital development during the last decade [21].

The third logic, control, is based on the assumption that outsourcing should be avoided in cases where there is a high risk of supplier opportunism. A dominant supplier with unique resources (high asset specificity) and an information advantage (information asymmetry) might behave opportunistically [22]. A supplier's high prices are not only a cost problem; the buyer also could lose control of lead times (time-to-market and time-to-customer), quality, and product development [23].

The fourth logic, flexibility, is important in its own right in a highly dynamic environment. It is tempting to try to transform fixed costs into variable costs by outsourcing [24-26], especially when companies face a need for investments in new machinery, factories, or IT systems. This situation can trigger outsourcing decisions. A combination of in-house production and outsourcing can also be a viable solution [20]. Furthermore, a high degree of uncertainty regarding new technology can lead to outsourcing as a firm seeks to maintain flexibility and reduce costs at the same time.

The fifth logic is access to superior external resources, which is the most relevant logic in this article. Deavers [27] mentioned access to world-class competence as one of the top five reasons for outsourcing. Others have made similar arguments [18,28,29]. The ability to exploit external resources puts the management of supplier relationships into focus.

\subsection{Analytical Model}

In the case of the automotive industry, Helper et al. [30] pointed out one major theoretical problem in their comparison of the American and Japanese automotive industries. They argued that the American strategy is a market organization while the Japanese strategy is a hybrid organization, which involves collaborative relationships with major suppliers. Their research sought to explain why the competitive American strategy has been less successful than the collaborative Japanese strategy. Even Japanese transplants in Great Britain and the United States have better key figures than the domestically owned factories. One explanation is that Japanese culture is more collaborative, but theoretically, many questions remain unanswered.

Whitford et al. [31] discussed collaboration starting from Granovetter [32] on the social embedding of economic actions. They looked "at boundaries between organizations by analysing the content and structure of ties between large manufacturers and their suppliers." Their conclusions take steps towards "a behavioural theory of the networked firm."

This analysis distinguishes between two dimensions that sometimes are treated as integrated in the discussion about core competence. One dimension is core value in the value proposition to customers, and the other is core competence or core capabilities as expressed in technology and processes (see Figure 1). This separation can be useful in several aspects, for instance if core values over time get separated from core competence and when new core competence must be sought outside the firm.

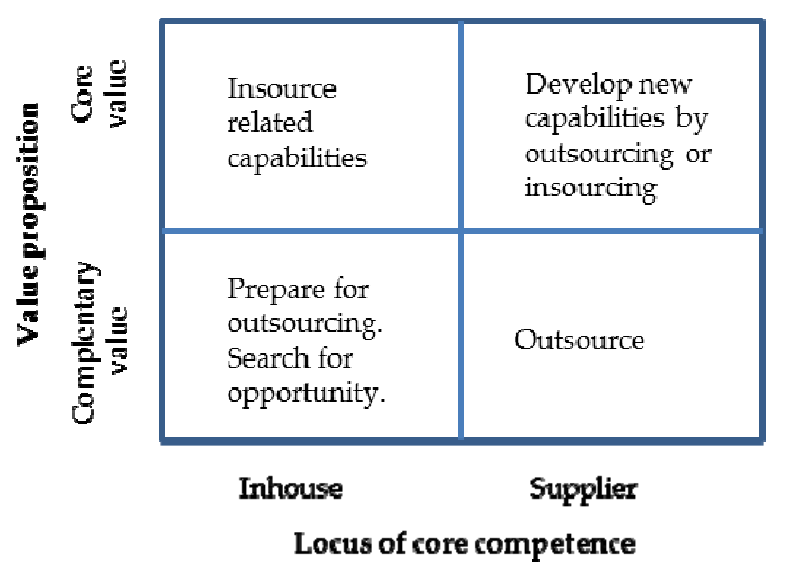

Figure 1. Analytical Model - Value types and locus of core competence

\section{A Note on Research Methods}

In case-based research, the choice of empirical cases is crucial $[33,34]$. Utilizing several longitudinal case studies is considered preferable for understanding an empirical context. The problem is basically a practical issue interviews are time-consuming and expensive. In this research, we concentrated on interviewing an OEMsupplier dyad - Volvo Personal Cars and Autoliv - over more than two decades.

Our initial contacts with Volvo Cars and Autoliv created interest in the topic, and the research period was extended beyond the first project. This research is now in its $18^{\text {th }}$ year, providing longitudinal data regarding the development of the relationship between Volvo Cars and Autoliv. Autoliv is also an important supplier to the other main competitors among the European OEMs - Saab, Audi, Mercedes, and BMW - all brands competing worldwide with Volvo.

The empirical data for this article was collected through a sequence of interviews with more than 25 individuals about equally divided between Volvo and Autoliv. The semi-structured interviews were conducting during 1994- 
2010 and were complemented with secondary data, such as reports, internal documents, and public material. The interviews included individuals from a variety of areas, such as product development, purchasing, general management, marketing management, and dealer management. Interviewees were introduced by people already interviewed, and sessions were taped or documented by two researchers to facilitate interpretation and to promote trustworthiness of the results.

\section{Recent trends and strategic focus in the automotive industry}

Making comparisons between automakers worldwide has been in vogue since the publication of The Machine That Changed the World [35] in 1990. Management strategies of innovation differentiate companies from each other [36], and the companies' relationships with suppliers also differ. Some mostly pursue a strategy of cooperation, and others focus on the freedom of choosing suppliers. The key issue is the search for the right combination of prices, quality, and services as well as innovation. A comparison of results of the applied strategies between 1990 and 2010 can illuminate some winning and losing (market share and financial performance) strategies.

Toyota and the Volkswagen Group have been the winners among the volume producers. The American Big Three (Chrysler, Ford, and GM) were the losers [1]. But since 2009, Toyota has been in deep trouble both financially and because of quality problems, which affected their supplier relationships. Among the premium brands, BMW and Lexus have been the winners; Volvo/Ford and Saab/GM among the losers. All these companies have ambitious programmes for more efficient engines with low emissions as well as a tradition of introducing innovations that attract customers to the brand.

Toyota is well known for lean production, with high quality and a complete line of brands and models. This automaker is very complex and deeply integrated in the Japanese culture, and therefore hard for automakers in other cultures to imitate. The mainstream literature on strategic management includes no clear interpretation of these strategies. Expansion of both markets and products [37], cost efficiency and differentiation [5], and core competence [3] are some of the references that could apply. Toyota's long-term perspective can be analysed using the BCG (Boston Consulting Group) matrix in which "Cash Cows" deliver resources to "Question Marks" and "Stars," which creates new "Cash Cows. Toyota (with Prius) and Lexus lead in hybrid and battery technology, an example of a long-term strategy producing Question Marks and later new Cash Cows. In 2012 Toyota came back as No, 1 global volume automaker ahead of General Motors [45].
Both Toyota and the American Big Three automakers are mass producers, but Japanese strategies differ from American ones [38]. Toyota has the lowest degree of global sourcing and the highest degree of in-house component deliveries [39]. With external major suppliers, Toyota has a collaborative strategy based on a strong interaction between customer and supplier aimed at consolidating their partnership to deal with any mutual problem (defects in supply, efficiency losses, and so on) that may emerge over time. Toyota is a global automaker, with direct investments in the United States and 13 manufacturing locations (in 2010). GM, Ford, and Chrysler's strategies are typical for global mass production automakers with an arm's length relationship with suppliers. Their supplier relationships are based on the belief that no contract lasts forever and everything depends on the most attractive offer (prices, quality, and services). Innovation is not a prime factor in supplier selection. The Porter [5] model clearly depicts American mass production as a cost-efficient strategy; however, Helper et al. [30] explain why this strategy is not competitive and lacks innovative focus. Global sourcing as a part of the mass production strategy does not offer enough resources for R\&D and new products. Overall, this purchasing strategy has failed.

The Volkswagen Group (Audi, VW, Skoda, and Seat) has a high degree of global sourcing. But lately the company has also organized an internal component division. The product strategy is to build several models per platform to take advantage of both economies of scale and scope. The VW Group embraces a mix of strategies; at the same time, they are cost efficient and differentiated. Seat is a mass production product and Audi is a premium car on top of the product line that has successfully competed with BMW and Mercedes. Both market share and financial performance have been among the best in the class. However, Porsche's unfriendly takeover attempt in 2008 and 2009 in which VW acquired Porsche instead, was devastating for financial stability. Both companies made financial losses during the conflict.

Premium brands have a significantly higher price per kilo than mass-produced brands in the same bracket (sedan, SUV, and so on). BMW's strategy is differentiation by technical leadership, advanced design, and high performance, clearly depicted in the Porter [5] model. But with a long history in the German high-technology culture, BMW presents a complex picture, and is not without problems. After having developed a profile with powerful engines, BMW now delivers engines with sufficient power, fuel efficiency, and low emissions. The company faces the challenge of how to split its image to appeal to different buyer preferences and governmental demands for emission controls. 
Saab and Volvo have been caught up in the strategies of their American owners, and have lost their brand image. GM sold Saab Automobile to Spyker Cars, NL, after 20 years, and Ford sold Volvo to the Chinese company Geely after 15 years. The future is problematic for both Swedish automakers, which have been "stuck in the middle." Even as Volvo's volumes have been two to three times as high as Saab's, both have been too small for scale economies. Yet Volvo was profitable almost continually from its founding in 1926 until 2009, and the company's long-term successful differentiation strategy resulted in a reputation for safety. Although most competitors have the same ranking in NCAP safety tests, Volvo has a leading position and image in safety systems, a product of an historical Swedish safety culture. On the other hand, Saab has jumped between different images and has lost market shares. Saab was profitable only during a short period from its founding in 1946, as a part of a diversification strategy within the Swedish defence/airspace industry. Saab Automobile went bankrupt in 2011.

The winners have demonstrated "dynamic capabilities" [40] with their ability to develop new products and systems over and over again. This is an "ex post fact" and an inspiring challenge for creation of winning strategies, but is it a generative concept for those who are in deep trouble, the losers? From 2010, we can expect that the development of green technologies in the car industry will require new competence and heavy investments. At the same time, the largest automakers will reduce their capacity in the United States and the European Union by 20 to 25 per cent as they expand in growing markets such as China and India [1]. In this situation, suppliers have a key role.

Major challenges for the next decade are the power train and fuel efficiency for emissions reduction. Most automakers have a weak financial status following the economic crisis of 2008. However, national governments and political institutions such as the European Union can be expected to support green technology development. This process has already begun in the United States, Japan, and the European Union, with plug-in electric cars, hybrid engines and new battery technologies.

\section{Four Types of Supplier Relationships}

The core competence for green technology development lies in the hands of power companies and the electronic and computer industries (battery technology). Will they emerge as new partners in product development in the automotive industry? Will the automakers accept becoming dependent on outside suppliers for core technologies? How can automakers develop and protect unique competence in a collaborative strategy?
According to our analysis, part of the answer can be found in the leading safety systems (safety belts and airbags) developed through the close relationships between Volvo and Autoliv. The steelmaker SSAB also contributed new materials and designs for passenger protection. Safety is Volvo's most important core competence, but one it shares with the suppliers Autoliv and SSAB, which also serve Volvo's competitors. These examples involve OEM-supplier relationships that can be a role model for more collaborative product development and purchasing strategies in the automotive industry. The following citation demonstrates Volvo's awareness of the importance of stimulating collaboration in a specific way:

A key factor for Volvo is to ensure that Autoliv can attract development assignments from several OEMs. If not, their new product development portfolio would contain fewer projects, which over the time will make it more difficult for Volvo to rely on Autoliv for our future profile as a safety-focused brand. (Product Development Manager, Volvo)

We identified different relationships and the respective key issues and problems that develop over a product's life cycle, from new product development (NPD), to production, to delivery. The relationships studied were in areas of the technologically intensive, internal and external safety. When identifying different supplier relationships, in our coding of the interviews and categorization we studied product novelty, knowledge intensiveness, risk, and uncertainty, as well as the structure and organization of the relationship. Drawing on previous studies on categorization of supplier relationships [41,30,42], we identified four relationship types (Table 1 ).

\subsection{Selected Supplier Strategy}

In Volvo's case, safety has been a major issue since the late 1960s. The development of the three-point safety belt and other safety systems emerged from a mixture of internal knowledge and knowledge from selected suppliers. The linkages between different subsystems, systems, and modules in the organization of product development reflect the technology of the final product.

After establishing the goals for product development, the process can be deconstructed into specifications of subsystems. In the next step, the specifications are translated into requirements for components. As a supplier, Autoliv is involved in specific product/function development, and lacks knowledge of the total development project. 


\begin{tabular}{|c|c|c|}
\hline & Key drlver & Relationship characteristics \\
\hline 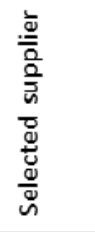 & $\begin{array}{l}\text { Covering } \\
\text { shur lages in uwn } \\
\text { R\&D capacity }\end{array}$ & $\begin{array}{l}\text { - } \quad \text { Long-term relationships } \\
\text { - } \\
\text { Differ enl curltracts for } \\
\text { R\&D and delivery of } \\
\text { products } \\
\text { - } \\
\text { Limited integration (not } \\
\text { shared responsibility) }\end{array}$ \\
\hline 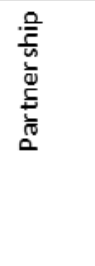 & $\begin{array}{l}\text { Shorten time-to- } \\
\text { market } \\
\text { Integration of } \\
\text { R\&D, production } \\
\text { and delivery of } \\
\text { subsystems }\end{array}$ & $\begin{array}{l}\text { - Relationship established } \\
\text { for the product lifetime } \\
\text { - Intensive integration } \\
\text { and shared meetings } \\
\text { between OEM and } \\
\text { supplier }\end{array}$ \\
\hline 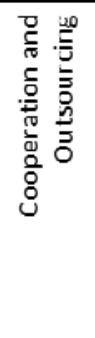 & $\begin{array}{l}\text { Acquring and } \\
\text { utilizing supplier } \\
\text { knowledge }\end{array}$ & $\begin{array}{l}\text { - OEM focused more on } \\
\text { getting high technical } \\
\text { solutions than on a } \\
\text { unique subystem } \\
\text { - Supplier increases its } \\
\text { knowledge through } \\
\text { projects with several } \\
\text { OEMs and shared } \\
\text { solutions }\end{array}$ \\
\hline 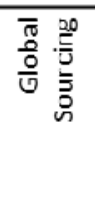 & $\begin{array}{l}\text { Cost and volume } \\
\text { of components of } \\
\text { higher valuc than } \\
\text { technical novelty }\end{array}$ & $\begin{array}{l}\text { - R\&D handled in a } \\
\text { contractual way with IPR } \\
\text { Scparatc contracts for } \\
\text { R\&D, production and } \\
\text { delivery }\end{array}$ \\
\hline
\end{tabular}

Table 1. Identified supplier relationship strategies in the VolvoAutoliv case

Procurement takes place on the component level. In this type of supplier relationship, a high level of internal R\&D and technical competence on the integration of subsystems and components into the final car are important to Volvo.

Crash safety performance depends on seamless integration of R\&D in different areas. We work in some of these areas inhouse and knowledge of the others is available through our core suppliers. We have worked together and persons have been working both on the Volvo and Autoliv side, so everyone knows which knowledge they have. However, the engineering design decisions need to be coordinated, and that is a core issue for Volvo. (Engineering Manager, Volvo)

For top management, this type of supplier relationship has potential problems. The supplier is providing complementary value to the product development. The buying company, not the supplier, makes the product competitive on the market. In the Volvo-Autoliv case, we found that this relationship can develop further if both companies are open to mutual commitments. This type of relationship is also present in Volvo's contracts with technical consultant firms that provide $R \& D$ knowledge capacity to different projects.

\subsection{Partnership Strategy}

Our relationship expanded as the market demands for safety equipment took off in the 1970s. Volvo decided to make safety one of their top priorities in development as well as marketing with the 240 -series and at that time a number of individuals in Autoliv's development group came from Volvo. Through this way to organize (joint development groups) we created a relationship on individual level and a joint technology agenda that was beneficial for Autoliv as well as Volvo." (Business Director, Autoliv)

For Volvo, the focus on handling R\&D-related issues separately from production and delivery contracts became too expensive for its competitive advantage. The rationale for the development of a partnership-based supplier strategy was to use it as a way to change the traditional task-specific sequential culture. Instead, an overlapping culture was established in which the final outcome was more important than the formal sequence. This strategy aligns with the strategic thinking of Japanese suppliers and a belief that by developing a supply system (integration of R\&D, production, and delivery), the cost for each component can be reduced [35].

In its new role, first introduced in the early 1990s, Volvo took responsibility for developing the total car concept and coordinating the supply system. The Volvo analysis revealed that the only way to be first to market in product development was to cooperate with large and resourceful suppliers. A new competence of handling supplier partnerships was developed, as well as knowledge regarding the organizational form that produces an operational and effective partnership. When the Volvo managers and purchasers described the core competence and values, they often came back to three values: safety, environment, and quality.

Today we have a narrow and deep competence to construct and produce a few car models. In the future, we will need a broad and superficial competence to deal with more car models and place demands on our suppliers instead of doing things ourselves. (Purchaser, Volvo, 1994)

The new supplier relationship strategy had strong intellectual influences from Chrysler's success in the 1980s. Partnership with world-class suppliers was a key parameter in the new strategy. Volvo said that they wanted to be "the best customer in the world together with world-class suppliers" that could cooperate both in product development and production. A high pace in development and a broad range of car models were becoming more and more important. To take advantage of the suppliers' competence and capacity, Volvo 
developed partner relationships with its major direct suppliers. Autoliv was one of them from the very beginning. Single sourcing was the most realistic strategic choice considering that Volvo was a small OEM in volume.

\subsection{Cooperation and Outsourcing Strategy}

The question of even faster introduction of products forced a radical shift in the OEMs' scope and the structure of their product development processes. In cooperation with Japanese companies (Mitsubishi, for example), Volvo realized that it could structure supplier relationships in different ways to acquire and utilize suppliers' knowledge. New methods of cooperating and outsourcing were established to handle the complex tasks of product development, production, and delivery, and to achieve results in innovation, time-to-market improvements, and cost reduction. The focus of the supplier relationship shifted from creating unique solutions to utilizing the full measure of the supplier's knowledge and skills. Uniqueness developed by integrating different components/products that are difficult for a competitor to copy. Autoliv has a large portfolio of components/products with the potential to be developed into unique competitive products and systems if the supplier relationship is based on a mutual sharing of knowledge and experiences.

Autoliv operates development projects with Volvo's competitors. But, based on trust, Autoliv has satisfactorily solved the organizational problem in this process.

With so few suppliers in the world, we know which other OEMs Autoliv is working with. As long as we don't lose access to innovations that are funded by us, or as long as actions taken by the supplier do not harm our market position as leader within the safety area, we think this kind of "coopetition" is better than the alternatives. (Product Development Director, Volvo)

Upcoming problems can lead to improvement of the R\&D competence at Volvo's project team when the supplier is given greater responsibility. The use of suppliers who are partners increases Volvo's system competence. For example, a supplier like Autoliv has customers worldwide and develops three to five projects simultaneously. This pace is much higher than what Volvo could perform. Furthermore, the different demands from automakers put additional demands on the supplier for innovation, quality, and performance. Engineers in Volvo projects can take advantage of general experience gained from other customers' projects with Autoliv. A potential problem for Volvo is losing know-how to the supplier, which could change the balance of power in the relationship. However, we found that factors such as commitment, confidence, and trust were critical risk-limiting factors for both Autoliv and Volvo.

\subsection{Global Sourcing Strategy}

The fourth supplier relationship strategy identified between Volvo and Autoliv is characterized by a global focus on suppliers. These firms may supply proprietary parts, in which the majority of the components are standard items from a supplier-provided catalogue, and/or utilize functional definitions from Volvo describing the necessary function of components or systems while leaving the design and choice to the supplier. In this sourcing strategy, innovation and new knowledge are less important than the cost per item.

In some areas, it is not important for us to have a unique component, if the cost difference is 1 to 3 . Instead, we can work more on other components or systems. The importance is placed more on issues that support the brand than on technical novelty, and we rely on our suppliers' R\&D. (Systems Engineer, Volvo)

To be a global supplier, we must not only deliver just-intime worldwide; we must be able to sell the same components on all markets. This drives volume, volume drives the costs down, and low cost attracts the customers; worldwide customers drive the volume even more. (R\&D, Autoliv)

In the global sourcing strategy, the supplier is compared to other suppliers and the relationship does not depend on developing trust. Consequently this strategy is more applicable to standard components of a commodity nature, even if the components as such can be very good technologically and sophisticated, like seat belt retainers. For premium car manufacturers, this strategy must be applied carefully in order not to threaten the brand in the end customers' eyes. For Volvo, as part of a global purchasing organization, it is essential that the safety system be designed as a combination of commodities and special components, designed and manufactured for a specific vehicle model. In this case, the cooperation and outsourcing strategy is more suitable.

\section{Discussion and Conclusion}

Collaborative relationships require partners to contribute some of their managerial and technical expertise to the relationship. This transfer of knowledge can be a valuable source of ideas for improvement because both parties are required to prepare and organize operations in which they are highly skilled to match the type of relationship.

One commonly discussed difference between American and Japanese strategies is the organization of purchasing and product development. Japanese automakers and their major direct suppliers normally have collaborative 
relationships [30,42], while Americans typically favour relationships at arm's length. This case study of Volvo and Autoliv is a success story and a possible role model for collaborative automaker-supplier strategies for longterm development projects. The four different strategies identified target different aspects of the value types and locus of the core competence matrix (see Figure 2).

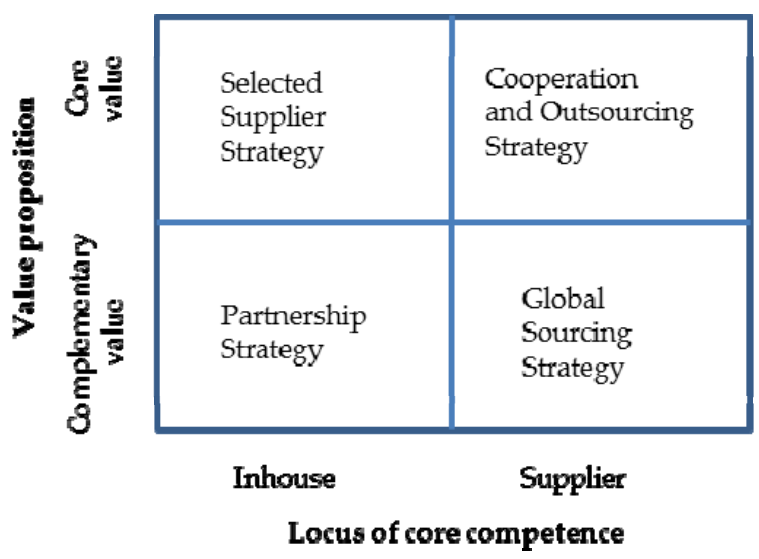

Figure 2. Supplier strategies in relation to value proposition and core competence locus

The combination of supplier and buyer competences leads to joint capabilities based on a unique strategic combination. The buyer's competitive positions rely on the suppliers' resources and capabilities as well as the chosen inter-firm relationship. Basing competitive advantage on the suppliers' competences requires the buyer to build and maintain appropriate routines and processes and to work with suppliers possessing complementary competences [44].

Looking forward, green technology leading to lower emissions will be a necessary component in the strategy and investment plans of winners in the future car market. With financially weakened automakers and the US government's bailout of GM, political interventions in the automotive industry can be expected to prevent social unrest and facilitate development of more fuel-efficient engines.

Based on the four different supplier strategies of the Volvo-Autoliv relationship, we found the "selected supplier strategy" (upper left quadrant in Figure 2), in which the core competence of the buyer drives the development of the relationship with the supplier, to be supportive in distinctive and focused areas. In the future, this is not a likely development path for OEM-supplier relationships.

Using the "cooperation and outsourcing strategy" (upper right quadrant, Figure 2), the OEM bases its competitive advantage on suppliers. The choice of supplier(s) is based on historical experience of communication and trust on different levels between the parties. Because of expected high investments in new technology, over time this strategy can be expected to contribute heavily to the OEMs' competitive power. According to textbook ideas, it is not a preferable situation to have core competences located at the supplier, but the Volvo-Autoliv case indicates that this contributes to both parties' competitive advantage.

The opposite applies to the "global sourcing strategy" (lower right quadrant, Figure 2). In a situation with new technology and technology shift, suppliers are seldom interchangeable and the managers' focus should not be on costs in isolation. The relative importance of the global sourcing strategy can be expected to decrease in the future.

The "partnership strategy" (lower left quadrant, Figure 2) indicates a situation in which the OEM has high technical knowledge supported by the suppliers' competences. Each component alone does not have sufficient competence for technological development, but through the partnership strategy the competences are pooled. In many situations, the OEMs have partnership strategies on development issues with different suppliers, of which only a limited number will lead to products that are introduced in the OEM's vehicle programme. In this case, Volvo launched several development initiatives with Autoliv, which strengthened both companies' competence although not all resulted in products.

The problem for the OEMs is to determine which competence they should strengthen internally and which is dependent on a partnership relationship with a supplier. If the two parties do not agree on the partnership's future direction, the drive to deepen the relationship is not mutual; for example, this may be the case if the OEM stresses the cost dimension so much that the supplier sees no future in maintaining the partnership.

This situation may arise in the future in areas in which the technical path is unclear. None of the parties may desire to focus all their efforts on a single partnership if insufficient knowledge and competences result.

Based on the Volvo-Autoliv longitudinal case study, we conclude that the winners in the automobile industry from 2010 on will be those that can organize long-term collaborative partnerships with their suppliers and political stakeholders, outsourcing a large part of technical development to the suppliers, both near the core competences and in crossover supply management with new technology (computer and power industry). In comparisons of German and Japanese automakers with primarily American manufacturers, we conclude that the buyer-supplier cooperation model of the former seems to 
be more fruitful. When the buyers (automakers) become more financially strained, they must also rely more heavily on suppliers for product development of systems and modules.

Automakers must accept that their external suppliers have competitors as their customers. This strategy provides shorter time-to-market and economies of scale in R\&D, product development, and production. Overall, we conclude that all empirical evidence indicates the importance of pragmatic, collaborative relationships between automakers and their first-tier suppliers, a conclusion that aligns with other reported findings $[41,38,30]$.

\section{References}

[1] ACEA (2010). The European Automobile Industry Association, Industry Report 2009. Brussels.

[2] Cox, A (1996) Relational competence and strategic procurement management - Towards an entrepreneurial and contractual theory of the firm, Eur. J. Pur. Supply Manag. 2 (1): 57-70.

[3] Prahalad, CK and Hamel, G (1990), The Core Competence of the Corporation, Harvard Bus. Rev. May-June, 2-15.

[4] Stalk, G and Evans, P (1992) Competing on capabilities: The new rules of corporate strategy, Harvard Bus. Rev. Apr/March, 70 (2), 57-69.

[5] Porter, ME (1980). Competitive Strategy. Techniques for analysing industries and competitors. New York, Free Press.

[6] Porter, ME (1985). Competitive Advantage. New York, Free Press.

[7] Brandes, H, Lilliecreutz, J and Brege, S (1997). Outsourcing - success or failure? Findings from five case studies, Eur. J. Pur. Supply Manag. 3 (2): 63-75.

[8] Lonsdale, C and Cox, A (1997). Outsourcing: risk and rewards, Supply Manage. 3: 32-34.

[9] McIvor, RT, Humphreys, PK and McAleer, WE (1997). A strategic model for the formulation of an effective make or buy decision, Manage. Decis. 35 (2): 169-178.

[10] Williamson, OE (1979). Transaction-cost economics: The governance of contract relations, J. Law Econ. 22, 3-61.

[11] Rindfleich, A and Heide, JB (1997). Transaction Cost Analysis: Past, Present and Future Applications, J. Marketing, 61 (October): 30-54.

[12] Bain, JS (1968). Industrial Organization, New York, John Wiley \& Sons Inc; 22nd Rev. Edition.

[13] Caves, R (1998). Industrial Organization and New Findings on the Mobility and Turnover of Firms, J. Eco. Lit. 36 (December) 1947-1982.

[14] Scherer, FM (1971). Industrial Market Structure and Economic Performance. Chicago, Rand McNally \& Co.
[15] Grant, RM (1991). The Resource-Based Theory of Competitive Advantage: Implications for Strategy Formulation, Calif. Manage. Rev. (Spring) 114-135.

[16] Javidan, M (1998). Core Competence: What Does it Mean in Practice. Long Range Plann. 31 (1): 60-71.

[17] Quinn, JB and Hilmer, F (1994), Strategic Outsourcing: Sloan Manage. Rev. Summer 43-55.

[18] Harrison, B and Kelly, MR (1993). Outsourcing and the Search for Flexibility, Work. Employ. Soc. 7 (2): 213-235.

[19] Hamel, G and Hene, A (1994). Competence-based competition. Chichester, Wiley.

[20] Nordigarden, D (2007). Outsourcing in the Wood Product Manufacturing Sector: A combined Customer and Supplier Perspective, Dissertation, Linkoping University.

[21] Espino-Rodriguez, TF and Padron-Robaina, V (2006). A review of outsourcing from the resource-based view of the firm, Int. J. Manag. Rev. 8(1), 49-70.

[22] Lonsdale, C (2001). Locked-in to Supplier Dominance: On the Dangers of Asset Specificity for the Outsourcing Decision, Supply Chain Manage. 4 (4): 176-183.

[23] Andersson, D, Brege, S Nordigarden, D and Rehme, J (2008). Outsourcing of Wood-Based Component Manufacturing: Driving Forces found in Scandinavian Companies, J. Forest Prod. Bus. Res. 4 (7): 78-94.

[24] Greaver, MF (1999). Strategic outsourcing: a structured approach to outsourcing decisions and initiatives. New York, AMACOM.

[25] Abrahamsson, M Andersson, D and Brege, S (2003). Outsourcing - Från mode och trend till balanserat strategibeslut (Outsourcing - From fashion and trend to a balanced strategy), Manage. Magazine, 5: 18-29.

[26] Carlson, M and Lind, J (2005). Management Control, an Alternative to Outsourcing (Alternativ till outsourcing), ed. Bengtsson, L Berggren, C Lind, J. Malmo, Liber.

[27] Deavers, KL (1997). Outsourcing: A Corporate Competitiveness Strategy, Not a Search for Low Wages, J. Labor Res., 18 (4), 503-519.

[28] Fine, CH and Whitney, DE (1999). Is the make-buy decision process a core competence?, Working paper from MIT Center for Technology, Policy and Industrial Development, MIT, Cambridge, MA.

[29] Quinn, JB (2000), Outsourcing innovation: The new engine of growth, Sloan Manage. Rev. 41(4), 13-28.

[30] Helper, S MacDuffie, JP, and Sabel, C (2000). Pragmatic Collaborations: Advancing Knowledge While Controlling Opportunism, Ind. Corp. Change, 9 (3), 443-488.

[31] Whitford, J Simmons, S, and Helper, S (2007). Contested Collaboration: Toward a behavioural theory of the networked firm. NY: Columbia University. Unpublished MS. 
[32] Granovetter, M (1985). Economic Action and Social Structure: The Problem of Embeddedness, Am. J. Sociol. 91(3), 481-510.

[33] Yin, R (1999) Case Study Research: Design and Methods. Thousand Oaks, Sage.

[34] Eisenhardt, KM (1989) Building theories from case study research, Acad. Manage. Rev. 14 (4), 532-550.

[35] Womack, JP, Jones, DT and Roos, D (1990). The Machine That Changed the World. New York, Rawson Associates.

[36] Volpato, G (2004). The OEM-FTS relationship in automotive industry, Int. J. Auto. Tech. Manage. 4 (2/3), 166-197.

[37] Ansoff, I (1965). Corporate Strategy. New York, McGraw Hill.

[38] Dyer, JH and Nobeoka, K (2000). Creating and Managing a High-Performance Knowledge-Sharing Network: The Toyota Case. Strategic Manage. J. 21: 345-367.

[39] Mueller, HE (2009). Strategic Partnerships in Automotive Supply Chains - The Case of GM, Toyota and VW. European Institute of Management Studies (EIASM) 7th Workshop, Helsinki.
[40] Teece, DJ, Pisano, G, and Shuen, A (1997). Dynamic capabilities and strategic management. Strategic Manage. J. 18 (7), 509-533.

[41] Lorenzoni, G, and Lipparini, A (1999) The Levering of Interfirm Relationships as a Distinctive Organizational Capability: A Longitudinal Study, Strategic Manage. J. 20, 317-338.

[42] Smals, RGM, and Smits, AAJ (2012), Value for Value - The dynamics of supplier value in collaborative new product development, Ind. Market. Manag. 41, 156-165.

[43] Sako, M (2004). Supplier development at Honda, Nissan and Toyota: comparative case studies of organizational capability enhancement, Ind. Corp. Change 13 (2) 281-308.

[44] Dyer, JH and Singh H (1998). The relational view: cooperative strategy and sources of interorganisational competitive advantage, Acad. Manage. Rev. 23, 660-679.

[45] Kageyama, Y. Toyota No. 1 again with nearly 9.75M sales in 2012, Associated Press, www.ap.org (201301-28). 